\title{
Pathophysiology and treatment of patients with globus sensation -from the viewpoint of esophageal motility dysfunction-
}

\author{
Noriaki Manabe $^{1}$, Hideaki Tsutsui ${ }^{2 *}$, Hiroaki Kusunoki ${ }^{3}$, Jiro Hata ${ }^{1}$ and Ken Haruma ${ }^{2}$ \\ ${ }^{1}$ Division of Endoscopy and Ultrasonography, Department of Clinical Pathology and \\ Laboratory Medicine, Kawasaki Medical School, Kurashiki, Japan \\ ${ }^{2}$ Division of Gastroenterology, Department of Internal Medicine, Kawasaki Medical School, \\ Kurashiki, Japan \\ ${ }^{3}$ Department of Health Care Medicine, Kawasaki Medical School, Kurashiki, Japan
}

Submitted January 8, 2014; accepted in final form September 2, 2014

\begin{abstract}
"Globus sensation" is often described as the sensation of a lump in the throat associated with dry swallowing or the need for dry swallowing, which disappears completely during eating or drinking and for which no organic cause can be established. Due to the uncertain etiology of "globus sensation", it remains difficult to establish standard treatment strategies for affected patients. Lately most attention has been focused on gastroesophageal reflux disease and several reports have indicated that there is a close relationship between esophageal acid reflux and globus sensation. Nowadays, empirical therapy with a high dose of a proton pump inhibitor (PPI) is considered to be indicated for patients with globus sensation, after excluding organic diseases such as pharyngeal cancer, Zenker's diverticulum, or thyroid enlargement. If patients are nonresponsive to PPI therapy, evaluation of esophageal motility should be done. In our recent study, $47.9 \%$ had abnormal esophageal motility, with the most common esophageal motility abnormality being an ineffective esophageal motility in PPI-resistant patients with globus sensation. This suggests that prokinetics alone or adding prokinetics to PPI should be the treatment to be considered, although few studies have investigated the efficacy of prokinetics in the treatment of patients with globus sensation. If patients without any esophageal motility dysfunctions are nonresponsive to PPI therapy, either cognitive-behavioral therapy, anti-depressants, or gabapentin could be helpful, although further well-designed, randomized controlled large-scale studies will be necessary to determine the effectiveness of each treatment strategy on patients with globus sensation.
\end{abstract}

Key words: globus sensation, gastroesophageal reflux disease, proton pump inhibitor, esophageal manometry

*The Hirosi Kuriyama Award 2013 winner

Abbreviations used: GERD, Gastroesophageal reflux disease; GI, gastrointestinal; PPI, proton pump inhibitor; UES, upper esophageal sphincter.

Corresponding author: Noriaki Manabe, M.D., phD, Division of Endoscopy and Ultrasonography, Department of Clinical Pathology and Laboratory Medicine, Kawasaki Medical School, 577, Matsushima, Kurashiki, Okayama 701-1092, Japan Phone: 81-86-462-1111 Fax: 81-86-462-1199 e-mail: n_manabe@hkg.odn.ne.jp

(C)2014 The Japan Society of Smooth Muscle Research 


\section{Introduction}

It is approximately 2500 years since Hippocrates first noted globus pharyngeus (1). In 1707, Purcell (2) was the first to accurately describe the condition; he believed that globus resulted from pressure on the thyroid cartilage due to contraction of the strap muscles of the neck. In the past, globus was described as "globus hystericus" because of its frequent association with menopause or psychogenic factors. However, Malcomson (3) coined the more accurate term "globus pharyngeus" in 1968 after discovering that most patients experiencing globus did not have a hysterical personality.

"Globus sensation" is often described as the sensation of a lump in the throat associated with dry swallowing or the need for dry swallowing, which disappears completely during eating or drinking and for which no organic cause can be established. It is a common condition that accounts for approximately $4 \%$ of new referrals to ear, nose and throat clinics, and it is reported by up to $46 \%$ of apparently healthy individuals, with a peak incidence in middle age $(4,5)$. Although the prevalence of patients with globus sensation was high, the natural history of patients with globus sensation has not been fully elucidated. In the past, Rowley et al. showed that during the mean follow-up period of 7 years and 7 months, 55\% of patients with globus sensation were asymptomatic and $45 \%$ of patients had persistent symptoms, while no patient developed upper gastrointestinal malignancy (6). Despite the benign nature of the condition, the likelihood of long-term symptom persistence often leads to a reduction in their quality of life, due to the lack of a highly effective single treatment, attributable to the fact that its pathogenesis has been poorly understood.

Gastroesophageal reflux disease (GERD) is a condition that develops when reflux of gastric contents causes troublesome symptoms and/or complications (7). GERD has now been considered the most common gastrointestinal (GI) disease worldwide. Subsequent to this trend, burgeoning of clinical entities attributed to GERD has also occurred. These include many ear, nose and throat, pulmonary and allergic symptoms, which are collectively termed extra-esophageal reflux disease (8). Extra-esophageal reflux is thought to be one of main factors in the pathogenesis of globus sensation $(9,10)$.

In this review, we will first review potential causes and treatments for globus sensation, and then we will introduce our data about the efficacy of PPI therapy for Japanese GERD patients complaining of globus sensation and to elucidate the characteristics of esophageal motility in patients showing resistance to PPI therapy.

\section{Potential causes of globus sensation}

Until now, many causes of globus sensation have been suggested, and it has been linked to several conditions from organic diseases such as pharyngeal cancer (11), Zenker's diverticulum (12), or thyroid enlargement (13) to non-organic diseases such as functional diseases. Table 1 shows potential causes of globus sensation which have been reported in previous papers.

\section{Organic diseases causing globus sensation}

First of all, excluding organic diseases is clinically important. A recent study by Nagano et al. (14) showed that $36.5 \%$ of patients with globus sensation had esophageal diseases in the absence of an aberrant otorhinolaryngological region, which suggests that consideration of esophageal disorders is important in patients with globus sensation without laryngeal and hypopharyngeal findings. In our study (15), among the 350 patients complaining of globus sensation, 13 patients (3.7\%) had endoscopic evidence of organic disease, including 10 patients with esophageal cancer, 2 patients with pharyngeal cancer, and 1 patient with Zenker's diverticulum 
Table 1. Potential causes of globus sensation

Organic diseases

Gastroesophageal reflux disease

Pharyngeal inflammatory causes including: pharyngitis, tonsillitis and chronic sinusitis

Upper aerodigestive malignancy

Hypertrophy of the base of the tongue

Retroverted epiglottis

Thyroid diseases

Cervical heterotopic gastric mucosa

Rare laryngopharyngeal tumors

Dysfunction of salivary secretion

Non-organic diseases

Abnormal upper esophageal sphincter function

Esophageal motor disorders

Psychological factors and stress

Patients with globus sensation and/or dysphagia $(n=350)$

13 patients with organic disease were

excluded

Patients with globus sensation and/or dysphagia without organic disease $(n=337)$

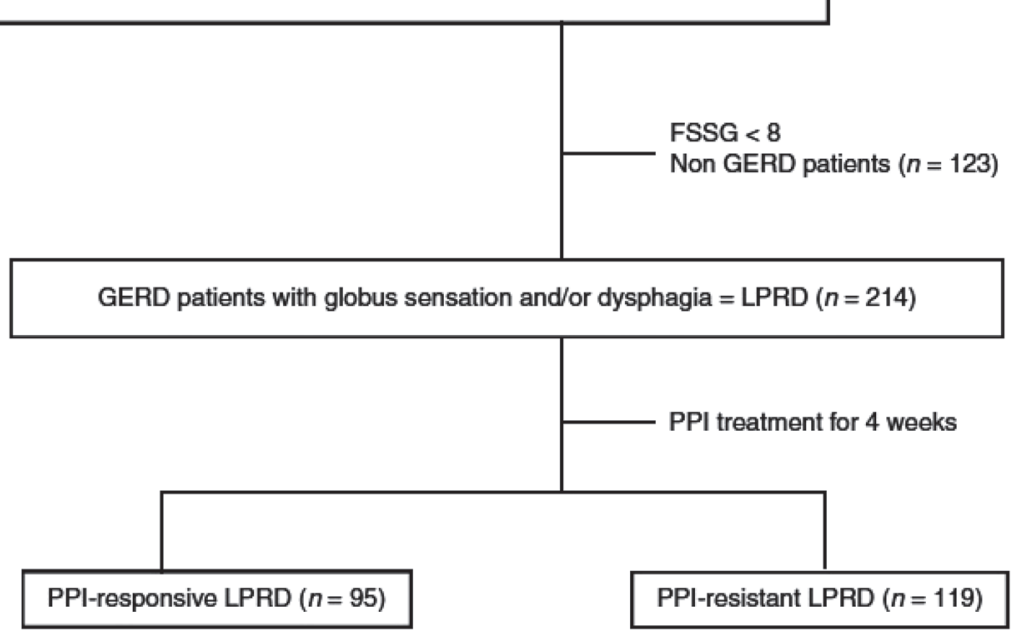

Fig. 1. Disposition of patients with globus sensation. From Tsutsui H et al. (15). Reproduction by copyright permission of Informa UK Ltd.

(Fig. 1). Based on these findings, otolaryngologists who generally do not use an upper GI endoscopy should remember that infection and malignant tumor cannot be ruled out by routine examination by otolaryngologists and such cases should be referred to a facility or department at which an upper GI endoscopy can be performed, when the symptom of globus sensation does not improve by any medication.

On the other hand, several recent papers have shown that globus sensation has also been linked to the presence of cervical hetrotopic gastric mucosa, from which acid secretion might cause the symptom of globus sensation (16-18). Furthermore, Alagozlu et al. revealed that Helicobacter pylori infection of the cervical hetrotopic gastric mucosa might be related to its symptom, although further studies will be necessary to confirm this result (19). 


\section{Association between globus sensation and GERD}

Although there is still considerable debate about the causative role of GERD patients complaining of globus sensation, gastroesophageal reflux has been suggested to be a major etiology of this symptom, potentially accounting for $23 \%-68 \%$ of patients with globus sensation $(20,21)$. A recent population-based study also showed that typical symptoms of GERD such as heartburn or regurgitation were associated with globus sensation (odds ratio: 3.9; 95\% confidence interval: 1.5-9.7) (22). In addition, it was reported that proximal acid exposure occurred in half of all patients with laryngeal symptoms (including globus sensation) or abnormal laryngoscopic findings, versus no GERD patients without laryngeal symptoms (23).

Currently, two main mechanisms are now thought to underlie the occurrence of globus sensation associated with acid reflux. First, acidic reflux into the esophagus may stimulate a vagal reflex that leads to the patient noting a globus sensation. Second, if refluxate passes into the larynx, direct contact with gastric acid and pepsin could cause mucosal injury that leads to the patient noting a globus sensation (9). Although both of these mechanisms are related to GERD, proton pump inhibitor (PPI) therapy often achieves disappointing results.

\section{Association between globus sensation and esophageal motility}

It has been reported that there is a high prevalence of esophageal motor abnormalities, including upper esophageal sphincter (UES) dysfunction (24), in patients who complain of globus sensation resistant to PPI therapy without any organic diseases, although the evidence obtained has been inconsistent.

\section{1) Abnormal upper esophageal sphincter function}

Abnormal UES function has been suggested to be one of the important causes of globus sensation (2528). Elevated UES pressure has been found to be significantly more frequent in patients with globus sensation than in controls ( $28 \%$ vs $3 \%$ ), suggesting that hypertensive UES is a crucial background factor for globus sensation (29). Another study to evaluate the effectiveness of injection of botulinum toxin into the cricopharyngeal muscle in patients with both globus sensation and high UES pressure showed that a decrease in UES pressure by botulinum toxin led to resolution of the globus sensation (25). In a recent study of high-resolution manometry in patients with globus sensation, normal controls, and GERD patients without globus sensation, hyperdynamic respiratory UES pressure changes were most prevalent in patients reporting globus sensation (28). However, results regarding to the UES function in patients with globus sensation were inconsistent because of a small number of subjects enrolled and differences in modalities used in each study (30-32).

\section{2) Esophageal motor disorders}

While there is some variation among previous studies, patients with globus sensation have been reported to have some kind of esophageal motor disorder, suggesting that esophageal motor disorders are a possible cause of, or a contributing factor in the development of globus sensation (33-36).

Moser et al. (37) noted that esophageal motor disorders might, before giving rise to dysphagia, be sensed more vaguely and induce the globus sensation. Esophageal manometry has revealed abnormalities in as many as $67 \%$ of patients with globus sensation, with nonspecific esophageal motility disorder being the most frequent finding (35). Our study to evaluate the characteristics of esophageal motility dysfunction in patients with globus sensation resistant to PPI treatment (15) showed that of the $47.9 \%$ of them that had abnormal esophageal motility, 66.4\% had ineffective esophageal motility (Fig. 2), 14.4\% had achalasia, 9.6\% had diffuse esophageal spasm, $8 \%$ had nutcracker esophagus, and $1.6 \%$ had hypertensive lower esophageal sphincter. This suggests that there were significant differences of UES pressure and esophageal body peristalsis between the patients 


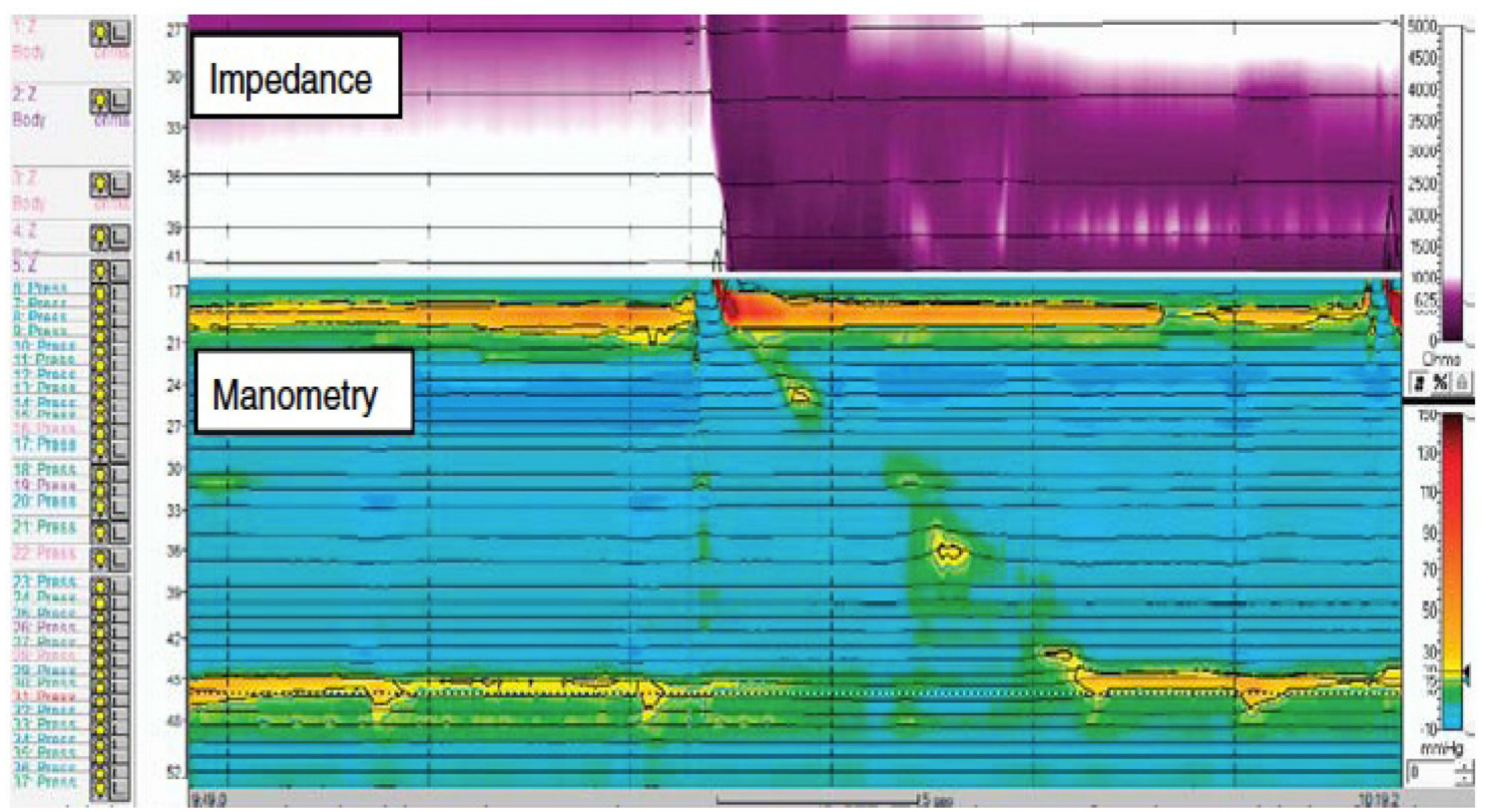

Fig. 2. Typical multichannel intraluminal impedance and manometry (MII-EM) image of patients with ineffective esophageal motility dysfunction: This is the case of a proton pump inhibitor (PPI)-resistant GERD patient complaining of globus sensation. The MII-EM shows that peristaltic dysfunction in the lower esophagus causes incomplete bolus transit. From Tsutsui H et al. (15). Reproduction by copyright permission of Informa UK Ltd.

Table 2. Comparison of esophageal function parameters between healthy controls and the proton pump inhibitorresistant GERD patients complaining of globus sensation groups

\begin{tabular}{lccc}
\hline & Healthy controls $(n=42)$ & PPI-resistant LPRD $(n=98)$ & $P$-Value \\
\hline Peak UES pressure after swallowing (mmHg) & $346.5 .1 \pm 81.2$ & $288.1 \pm 97.4$ & 0.0054 \\
Resting UES pressure (mmHg) & $71.1 \pm 31.0$ & $52.0 \pm 20.3$ & 0.0007 \\
UES relaxation duration (s) & $0.5 \pm 0.1$ & $0.5 \pm 0.1$ & N.S. \\
LES pressure (mmHg) & $16.7 \pm 6.0$ & $18.8 \pm 10.4$ & N.S. \\
Residual LES pressure (mmHg) & $2.2 \pm 2.7$ & $5.4 \pm 4.7$ & 0.0003 \\
Amplitude (20 cm above LES) (mmHg) & $39.1 \pm 16.8$ & $33.9 \pm 16.0$ & N.S. \\
Amplitude (15 cm above LES) (mmHg) & $50.3 \pm 21.8$ & $38.7 \pm 20.0$ & 0.0049 \\
Amplitude (10 cm above LES) (mmHg) & $63.0 \pm 19.0$ & $53.2 \pm 24.7$ & 0.0328 \\
Amplitude (5 cm above LES) (mmHg) & $78.0 \pm 26.8$ & $64.4 \pm 29.5$ & 0.0151 \\
Distal esophageal amplitude (mmHg) & $71.7 \pm 19.9$ & $59.6 \pm 25.4$ & 0.0084 \\
Velocity (cm/s) & $4.8 \pm 1.8$ & $3.9 \pm 1.8$ & 0.0181 \\
Peristaltic contractions (\%) & $90.5 \pm 10.8$ & $71.8 \pm 31.7$ & $<0.0001$ \\
Complete bolus transit (\%) & $83.5 \pm 10.9$ & $53.6 \pm 28.9$ & $<0.0001$ \\
\hline
\end{tabular}

Abbreviations: PPI = proton pump inhibitor, LPRD = laryngopharyngeal reflux disease, UES = upper esophageal sphincter, LES = lower esophageal sphincter. From Tsutsui H et al. (15). Reproduction by copyright permission of Informa UK Ltd.

with PPI-resistant GERD patients complaining of globus sensation and healthy controls matched for age and sex (Table 2).

Recently, one mechanism that was newly proposed is that globus sensation might in part be associated with excessive laryngeal and pharyngeal tension, although there are several points to address regarding this question (38). 
To validate the etiological significance of esophageal motility disorder in patients with globus sensation, further studies will be necessary to investigate whether the treatment of esophageal motility dysfunction would resolve globus sensation.

\section{Visceral hypersensitivity}

Visceral hypersensitivity has been identified in a number of functional gastrointestinal disorders including non-cardiac chest pain (39) functional dyspepsia (40) and irritable bowel syndrome (41). Chen et al. investigated the esophageal visceral perception in patients with globus sensation by using an esophageal balloon distension and electrical stimulation. They found patients with globus sensation demonstrate esophageal visceral hypersensitivity to mechanical distension: the differential responses to stretch and electrical stimuli may indicate that the hypersensitivity is a peripheral, rather than central phenomenon (42).

\section{Psychological factors and social stress}

It has been reported that several psychological problems or social stress have often been considered to cause or trigger globus sensation (43). In the past, several studies have shown that higher levels of psychological distress including anxiety or depression in patients with globus sensation (44), although a few data showed that there were no differences in the psychological states between patients with globus sensation and normal controls (34). A recent study showed that globus patients with laryngopharyngeal reflux (LPR) exhibited weaker psychological symptoms than non-LPR globus patients, and globus patients who did not respond to PPI had significantly higher anxiety scores (45), indicating a close relationship between psychological states and globus sensation.

\section{Treatment}

There have been no evidence-based treatment concepts available at this point in time, because of the few controlled trials for treatment of globus sensation. At present, there has been no single effective treatment for its symptoms. Therefore, the mainstays of its treatment are explanation and reassurance as for other functional gastrointestinal diseases (46). After explanation and reassurance, several possible treatment options based on the causes of globus sensation should be provided, such as anti-reflux therapy, therapy for improving gastrointestinal dysmotility including UES, treatment for decreasing the perception of globus sensation (visceral hypersensitivity), antidepressants and others.

\section{Acid suppressive therapy}

Since GERD is considered a major cause of globus sensation $(47,48)$, it seems reasonable that acid suppressive therapy such as PPI treatment should be the first-line therapy for patients with globus sensation after excluding organic diseases. Current evidence shows that the clinical response to PPI in patients with globus sensation is variable $(8,49)$ and that the symptom improves more slowly than typical GERD symptoms such as heartburn or regurgitation following acid-suppression therapy (20). Therefore, it is now widely accepted that patients with extra-esophageal GERD including globus sensation require more aggressive and more prolonged therapy than those with typical GERD (50). Empirical twice-daily therapy with PPI for at least 3 months is recommended; this can be extended for a maximum period of 6 months $(51,52)$. Our recent study that investigated the effectiveness of double doses of PPI (rabeprazole sodium at $20 \mathrm{mg}$ daily for 4 weeks) in GERD patients with globus sensation showed that the response rate with PPI was $44.4 \%$ and that PPI-responsive patients had 
significantly higher scores than the PPI-resistant patients for reflux-related symptoms (15). Our results suggested that the more acid reflux is involved in the etiology of patients with globus sensation, the more effective PPI becomes even though the duration of administration of PPI is relatively short. A recent study by Jeon et al. also showed the same results as ours, namely that the presence of reflux symptoms and short symptom duration were independent predictors of responsiveness to 4-week PPI treatment in patients with globus sensation (53).

However, recent studies have suggested some potential negative sequelae to long-term, high-dose PPI management (54). Therefore, it is necessary to remember that patients with globus sensation require more aggressive and more prolonged PPI therapy than those with typical GERD, and at the same time, prescribing a high dose of PPI for too long might lead to several side effects. Our data showed that $55.6 \%$ of GERD patients with globus sensation were resistant to PPI therapy, among whom $47.9 \%$ had abnormal esophageal motility with the most common esophageal abnormality being ineffective esophageal motility (15), suggesting that half of the patients with globus sensation basically are not related to acid reflux. We should change from PPI alone to another treatment such as prokinetics alone or adding prokinetics to PPI while monitoring its effectiveness in resolving patients' symptoms.

\section{Therapy for improving gastrointestinal dysmotility including UES}

A recent study suggested that stimulation of gastric emptying or esophageal clearance in addition to inhibition of gastric acid secretion may be an effective treatment for LPR. Ezzat et al. (55) reported that adding prokinetics, such as cisapride and itopride to PPIs to treat LPR reduced the recurrence of symptoms including globus sensation. Another recent study showed that rikkunshito, a Japanese herbal medicine, improved globus sensation in patients with PPI-refractory LPR, in part, because of stimulation of gastric emptying, suggesting that rikkunshito is an effective treatment for PPI-refractory LPR including globus sensation (21).

Furthermore, speech therapy has been successfully used to treat patients with persistent globus sensation to relieve vocal tract discomfort and tension (38). Recently Khalil et al. compared the efficacy of speech therapy to reassurance by a nurse practitioner for globus sensation, and found a significant improvement in the speech therapy group compared to controls (56). However, it is not clear whether there is a specific effect from the speech therapy or if the improvement is due to increased reassurance.

\section{Treatment for decreasing the perception of globus sensation (visceral hypersensitivity)}

Cognitive-behavioral therapy or antidepressants were considered as second-line or third-line therapy for patients with globus sensation.

\section{1) Cognitive-behavioral therapy}

It has been reported that a cognitive-behavioral therapy was the best treatment for a variety of somatoform disorders and medically unexplained symptoms (57). Therefore cognitive-behavioral therapy is now considered to be an effective therapy for patients with globus sensation, because globus sensation is the fourth most common symptom of somatization disorder after vomiting, aphonia, and pain in the extremities (58). Recently, Kiebles et al. also revealed that hypnotically assisted relaxation therapy could provide a substantial improvement in globus sensation irrespective of its cause, while esophageal motility including UES was unaffected (59). From their results of the combination of high responsiveness to hypnotically assisted relaxation therapy and no apparent impact on physiology, they speculated that globus sensation might be centrally mediated, although further studies will be necessary to address this question. 


\section{2) Antidepressants}

The visceral hypersensitivity is considered one of features of globus sensation (42), and might be modulated by antidepressant therapy. A close relationship has been reported between psychological states including depression and globus sensation. A small series of anti-depressants have also been found to be beneficial for some globus patients with concomitant psychiatric disorders, such as panic, somatization, major depression, and agoraphobia $(60,61)$.

Based on these findings, cognitive-behavioral therapy or antidepressants should be considered as secondline or third-line therapy for patients with globus sensation.

3) Gabapentin which is frequently used for neuropathic pain, migraine headaches, and nystagmus, or both

It is now recognized that neuralgia can cause cough and other head and neck symptoms including globus sensation (62-64). It has also been suggested that the globus sensation might actually be a peripherally-mediated phenomenon (42). Kirch et al. (65) investigated the effectiveness of treatment of globus sensation with PPI and/or gabapentin which is frequently used off-label for neuropathic pain, migraine headaches, and nystagmus, or both. In this study, $77 \%$ of patients with globus sensation could be helped by treating reflux or neuralgia. According to this result, they concluded that a trial of gabapentin should be considered for patients who do not respond or only partially respond to reflux management. They speculated that it might be a potential neurogenic cause for globus sensation because acid reflux irritates nerve endings in the esophagus, pharynx, or larynx.

\section{Other treatments}

There have been several other treatments in addition to the above therapies. First, thyroidectomy in patients with thyroid disorder (66) or partial epiglottectomy in selected cases whose retroverted epiglottis made contact with the tongue base $(67,68)$, were both reported to significantly relieve the globus symptom.

Second, recent several studies showed that an ablation of cervical heterotopic gastric mucosa by argon plasma coagulation had shown some promise in improving chronic globus symptoms $(69,70)$. Therefore, an ablation of cervical heterotopic gastric mucosa by argon plasma coagulation is considered to be one of the precious alternative therapies for patients with globus sensation resistant to any medical treatments.

\section{Closing remarks}

There is no standard treatment strategy for patients with globus sensation despite its common clinical symptom. It is partly because its etiology remains uncertain. Globus sensation has been known as one of the multifactorial diseases, and recent several studies show that GERD is a major cause of globus sensation as interests tend to focus on GERD. However, efficacy of PPI for patients with globus sensation is limited to clinical situations, suggesting that its etiology might not be always related to gastric acid reflux. Our recent study demonstrated that 4 weeks of double doses of PPI therapy was effective in only $44.4 \%$ patients with globus sensation and suggested that esophageal motility dysfunction (including UES dysfunction) plays an important role in the pathogenesis of PPI-resistant GERD patients with globus sensation. Although there have been appeared several promising therapies for these patients, no large studies to investigate its efficacy have been reported. In the future, well-designed, randomized controlled studies will be needed to definitively determine the effect of several treatment strategies on globus sensation, as well as to ascertain the etiology of globus sensation via large-scale studies. 


\section{Conflict of interest}

The authors have no conflict of interest.

\section{References}

1. Harar RP, Kumar S, Saeed MA, Gatland DJ. Management of globus pharyngeus: review of 699 cases. J Laryngol Otol. 2004; 118(7): 522-7.

2. Purcell J. A treatise of vapours or hysteric fits. 2nd ed. London: Edward Place; 1707. p. $72-4$.

3. Malcomson KG. Globus hystericus vel pharyngis (a recommaissance of proximal vagal modalities). J Laryngol Otol. 1968; 82(3): 219-30.

4. Moloy PJ, Charter R. The globus symptom. Incidence, therapeutic response, and age and sex relationships. Arch Otolaryngol. 1982; 108(11): 740-4.

5. Drossman DA, Li Z, Andruzzi E, Temple RD, Talley NJ, Thompson WG, Whitehead WE, Janssens J, Funch-Jensen P, Corazziari E, Richter JE, Koch GG. U.S. householder survey of functional gastrointestinal disorders. Prevalence, sociodemography, and health impact. Dig Dis Sci. 1993; 38(9): 1569-80.

6. Rowley H, O’Dwyer TP, Jones AS, Timon CI. The natural history of globus pharyngeus. Laryngoscope. 1995; 105(10): 1118-21.

7. Vakil N, van Zanten SV, Kahrilas P, Dent J, Jones R. Global Consensus Group. The Montreal definition and classification of gastroesophageal reflux disease: a global evidence-based consensus. Am J Gastroenterol. 2006; 101(8): 1900-20.

8. Vaezi MF, Hicks DM, Abelson TI, Richter JE. Laryngeal signs and symptoms and gastroesophageal reflux disease (GERD): a critical assessment of cause and effect association. Clin Gastroenterol Hepatol. 2003; 1(5): 333-44.

9. Tauber S, Gross M, Issing WJ. Association of laryngopharyngeal symptoms with gastroesophageal reflux disease. Laryngoscope. 2002; 112(5): 879-86.

10. Vavricka SR, Storck CA, Wildi SM, Tutuian R, Wiegand N, Rousson V, Fruehauf H, Mullhaupt B, Fried M. Limited diagnostic value of laryngopharyngeal lesions in patients with gastroesophageal reflux during routine upper gastrointestinal endoscopy. Am J Gastroenterol. 2007; 102(4): 716-22.

11. Tsikoudas A, Ghuman N, Riad MA. Globus sensation as early presentation of hypopharyngeal cancer. Clin Otolaryngol. 2007; 32(6): 452-6.

12. Odemis B, Ataseven H, Basar O, Ertugrul I, Yüksel O, Turhan N. Ulcer in the basis of Zenker's diverticulum mimicking esophageal malignancy. J Natl Med Assoc. 2006; 98(7): 1177-80.

13. Marshall JN, McGann G, Cook JA, Taub N. Prospective controlled study of high-resolution thyroid ultrasound in patients with globus pharyngeus. Clin Otolaryngol Allied Sci. 1996; 21(3): 228-31.

14. Nagano H, Yoshifuku K, Kurono Y. Association of a globus sensation with esophageal diseases. Auris Nasus Larynx. 2010; 37(2): 195-8.

15. Tsutsui H, Manabe N, Uno M, Imamura H, Kamada T, Kusunoki H, Shiotani A, Hata J, Harada T, Haruma K. Esophageal motor dysfunction plays a key role in GERD with globus sensation-analysis of factors promoting resistance to PPI therapy. Scand J Gastroenterol. 2012; 47(8-9): 893-9.

16. von Rahden BH, Stein HJ, Becker K, Liebermann-Meffert D, Siewert JR. Heterotopic gastric mucosa of the esophagus: literature-review and proposal of a clinicopathologic classification. Am J Gastroenterol. 2004; 99(3): 543-51.

17. Lancaster JL, Gosh S, Sethi R, Tripathi S. Can heterotopic gastric mucosa present as globus pharyngeus? J Laryngol Otol. 2006; 120(7): 575-8.

18. Alaani A, Jassar P, Warfield AT, Gouldesbrough DR, Smith I. Heterotopic gastric mucosa in the cervi- 
cal oesophagus (inlet patch) and globus pharyngeus - an under-recognised association. J Laryngol Otol. 2007; 121(9): 885-8.

19. Alagozlu H, Simsek Z, Unal S, Cindoruk M, Dumlu S, Dursun A. Is there an association between Helicobacter pylori in the inlet patch and globus sensation? World J Gastroenterol. 2010; 16(1): 42-7.

20. Oridate N, Takeda H, Asaka M, Nishizawa N, Mesuda Y, Mori M, Furuta Y, Fukuda S. Acid-suppression therapy offers varied laryngopharyngeal and esophageal symptom relief in laryngopharyngeal reflux patients. Dig Dis Sci. 2008; 53(8): 2033-8.

21. Tokashiki R, Okamoto I, Funato N, Suzuki M. Rikkunshito improves globus sensation in patients with proton-pump inhibitor-refractory laryngopharyngeal reflux. World J Gastroenterol. 2013; 19(31): 511824.

22. Cho YS, Choi MG, Jeong JJ, Chung WC, Lee IS, Kim SW, Han SW, Choi KY, Chung IS. Prevalence and clinical spectrum of gastroesophageal reflux: a population-based study in Asan-si, Korea. Am J Gastroenterol. 2005; 100(4): 747-53.

23. Jacob P, Kahrilas PJ, Herzon G. Proximal esophageal pHmetry in patients with reflux laryngitis. Gastroenterology. 1991; 100(2): 305-10.

24. Meier-Ewert HK, Van Herwaarden MA, Gideon RM, Castell JA, Achem S, Castell DO. Effect of age on differences in upper esophageal sphincter and pharynx pressures between patients with dysphagia and control subjects. Am J Gastroenterol. 2001; 96(1): 35-40.

25. Halum SL, Butler SG, Koufman JA, Postma GN. Treatment of globus by upper esophageal sphincter injection with botulinum A toxin. Ear Nose Throat J. 2005; 84(2): 74.

26. Watson WC, Sullivan SN. Hypertonicity of the cricopharyngeal sphincter: A cause of globus sensation. Lancet. 1974; 2(7894): 1417-9.

27. Hunt PS, Connell AM, Smiley TB. The cricopharyngeal sphincter in gastric reflux. Gut. 1970; 11(4): 303-6.

28. Kwiatek MA, Mirza F, Kahrilas PJ, Pandolfino JE. Hyperdynamic upper esophageal sphincter pressure: a manometric observation in patients reporting globus sensation. Am J Gastroenterol. 2009; 104(2): 289-98.

29. Corso MJ, Pursnani KG, Mohiuddin MA, Gideon RM, Castell JA, Katzka DA, Katz PO, Castell DO. Globus sensation is associated with hypertensive upper esophageal sphincter but not with gastroesophageal reflux. Dig Dis Sci. 1998; 43(7): 1513-7.

30. Caldarelli DD, Andrews AH Jr, Derbyshire AJ. Esophageal motility studies in globus sensation. Ann Otol Rhinol Laryngol. 1970; 79(6): 1098-100.

31. Cook IJ, Dent J, Collins SM. Upper esophageal sphincter tone and reactivity to stress in patients with a history of globus sensation. Dig Dis Sci. 1989; 34(5): 672-6.

32. Sun J, Xu B, Yuan YZ, Xu JY. Study on the function of pharynx upper esophageal sphincter in globus hystericus. World J Gastroenterol. 2002; 8(5): 952-5.

33. Wilson JA, Heading RC, Maran AG, Pryde A, Piris J, Allan PL. Globus sensation is not due to gastrooesophageal reflux. Clin Otolaryngol Allied Sci. 1987; 12(4): 271-5.

34. Batch AJ. Globus pharyngeus: (Part II), Discussion. J Laryngol Otol. 1988; 102(3): 227-30.

35. Färkkilä MA, Ertama L, Katila H, Kuusi K, Paavolainen M, Varis K. Globus pharyngis, commonly associated with esophageal motility disorders. Am J Gastroenterol. 1994; 89(4): 503-8.

36. Knight RE, Wells JR, Parrish RS. Esophageal dysmotility as an important co-factor in extraesophageal manifestations of gastroesophageal reflux. Laryngoscope. 2000; 110(9): 1462-6.

37. Moser G, Vacariu-Granser GV, Schneider C, Abatzi TA, Pokieser P, Stacher-Janotta G, Gaupmann G, Weber U, Wenzel T, Roden M. High incidence of esophageal motor disorders in consecutive patients with globus sensation. Gastroenterology. 1991; 101(6): 1512-21.

38. Khalil HS, Reddy VM, Bos-Clark M, Dowley A, Pierce MH, Morris CP, Jones AE. Speech therapy in 
the treatment of globus pharyngeus: how we do it. Clin Otolaryngol. 2011; 36(4): 388-92.

39. Richter JE, Barish CF, Castell DO. Abnormal sensory perception in patients with esophageal chest pain. Gastroenterology. 1986; 91(4): 845-52.

40. Mertz H, Fullerton S, Naliboff B, Mayer EA. Symptoms and visceral perception in severe functional and organic dyspepsia. Gut. 1998; 42(6): 814-22.

41. Mertz H, Naliboff B, Munakata J, Niazi N, Mayer EA. Altered rectal perception is a biological marker of patients with irritable bowel syndrome. Gastroenterology. 1995; 109(1): 40-52.

42. Chen CL, Szczesniak MM, Cook IJ. Evidence for oesophageal visceral hypersensitivity and aberrant symptom referral in patients with globus. Neurogastroenterol Motil. 2009; 21(11): 1142-e96.

43. Lee BE, Kim GH. Globus pharyngeus: a review of its etiology, diagnosis and treatment. World J Gastroenterol. 2012; 18(20): 2462-71.

44. Deary IJ, Wilson JA, Kelly SW. Globus pharyngis, personality, and psychological distress in the general population. Psychosomatics. 1995; 36(6): 570-7.

45. Siupsinskiene N, Adamonis K, Toohill RJ, Sereika R. Predictors of response to short-term proton pump inhibitor treatment in laryngopharyngeal reflux patients. J Laryngol Otol. 2008; 122(11): 1206-12.

46. Galmiche JP, Clouse RE, Bálint A, Cook IJ, Kahrilas PJ, Paterson WG, Smout AJ. Functional esophageal disorders. Gastroenterology. 2006; 130(5): 1459-65.

47. Hill J, Stuart RC, Fung HK, Ng EK, Cheung FM, Chung CS, van Hasselt CA. Gastroesophageal reflux, motility disorders, and psychological profiles in the etiology of globus pharyngis. Laryngoscope. 1997; 107(10): 1373-7.

48. Chevalier JM, Brossard E, Monnier P. Globus sensation and gastroesophageal reflux. Eur Arch Otorhinolaryngol. 2003; 260(5): 273-6.

49. Katz PO, Castell DO. Medical therapy of supraesophageal gastroesophageal reflux disease. Am J Med 2000; 108 Suppl 4a: 170S-7S.

50. Remacle M. The diagnosis and management of globus: a perspective from Belgium. Curr Opin Otolaryngol Head Neck Surg. 2008; 16(6): 511-5.

51. Celik M, Ercan I. Diagnosis and management of laryngopharyngeal reflux disease. Curr Opin Otolaryngol Head Neck Surg. 2006; 14(3): 150-5.

52. Remacle M, Lawson G. Diagnosis and management of laryngopharyngeal reflux disease. Curr Opin Otolaryngol Head Neck Surg. 2006; 14(3): 143-9.

53. Jeon HK, Kim GH, Choi MK, Cheong JH, Baek DH, Lee GJ, Lee HM, Lee BE, Song GA. Clinical predictors for response to proton pump inhibitor treatment in patients with globus. J Neurogastroenterol Motil. 2013; 19(1): 47-53.

54. Moayyedi P, Leontiadis GI. The risks of PPI therapy. Nat Rev Gastroenterol Hepatol. 2012; 9(3): 132-9.

55. Ezzat WF, Fawaz SA, Fathey H, El Demerdash A. Virtue of adding prokinetics to proton pump inhibitors in the treatment of laryngopharyngeal reflux disease: prospective study. J Otolaryngol Head Neck Surg. 2011; 40(4): 350-6.

56. Khalil HS, Bridger MW, Hilton-Pierce M, Vincent J. The use of speech therapy in the treatment of globus pharyngeus patients. A randomised controlled trial. Rev Laryngol Otol Rhinol (Bord). 2003; 124(3): 187-90.

57. Kroenke K. Efficacy of treatment for somatoform disorders: a review of randomized controlled trials. Psychosom Med. 2007; 69(9): 881-8.

58. Othmer E, DeSouza C. A screening test for somatization disorder (hysteria). Am J Psychiatry. 1985; 142(10): 1146-9.

59. Kiebles JL, Kwiatek MA, Pandolfino JE, Kahrilas PJ, Keefer L. Do patients with globus sensation respond to hypnotically assisted relaxation therapy? A case series report. Dis Esophagus. 2010; 23(7): 
545-53.

60. Cybulska EM. Globus hystericus-a somatic symptom of depression? The role of electroconvulsive therapy and antidepressants. Psychosom Med. 1997; 59(1): 67-9.

61. Brown SR, Schwartz JM, Summergrad P, Jenike MA. Globus hystericus syndrome responsive to antidepressants. Am J Psychiatry. 1986; 143(7): 917-8.

62. Morrison M, Rammage L, Emami AJ. The irritable larynx syndrome. J Voice. 1999; 13(3): 447-55.

63. Norris BK, Schweinfurth JM. Management of recurrent laryngeal sensory neuropathic symptoms. Ann Otol Rhinol Laryngol. 2010; 119(3): 188-91.

64. Lee B, Woo P. Chronic cough as a sign of laryngeal sensory neuropathy: diagnosis and treatment. Ann Otol Rhinol Laryngol. 2005; 114(4): 253-7.

65. Kirch S, Gegg R, Johns MM, Rubin AD. Globus pharyngeus: effectiveness of treatment with proton pump inhibitors and gabapentin. Ann Otol Rhinol Laryngol. 2013; 122(8): 492-5.

66. Maung KH, Hayworth D, Nix PA, Atkin SL, England RJ. Thyroidectomy does not cause globus pattern symptoms. J Laryngol Otol. 2005; 119(12): 973-5.

67. Agada FO, Coatesworth AP, Grace AR. Retroverted epiglottis presenting as a variant of globus pharyngeus. J Laryngol Otol. 2007; 121(4): 390-2.

68. Quesada JL, Lorente J, Quesada P. Partial epiglottectomy as a possible treatment for globus pharyngeus? Eur Arch Otorhinolaryngol. 2000; 257(7): 386-8.

69. Meining A, Bajbouj M, Preeg M, Reichenberger J, Kassem AM, Huber W, Brockmeyer SJ, Hannig C, Höfler H, Prinz C, Schmid RM. Argon plasma ablation of gastric inlet patches in the cervical esophagus may alleviate globus sensation: a pilot trial. Endoscopy. 2006; 38(6): 566-70.

70. Bajbouj M, Becker V, Eckel F, Miehlke S, Pech O, Prinz C, Schmid RM, Meining A. Argon plasma coagulation of cervical heterotopic gastric mucosa as an alternative treatment for globus sensations. Gastroenterology. 2009; 137(2): 440-4. 